\title{
APLICAÇÕES DA TERAPIA FOTODINÂMICA NA ODONTOLOGIA
}

\section{PHOTODYNAMIC THERAPY APPLICATIONS IN DENTISTRY}

\author{
Vanda Sanderana Macêdo Carneiro, Maria \\ Helena Chaves de Vasconcelos Catão
}

\author{
Universidade Estadual da Paraíba, Brasil \\ Mestranda em Clínica Odontológica pelo \\ departamento de Odontologia da UEPB.
}

\section{Resumo}

A Terapia Fotodinâmica (TFD) baseia-se na administração tópica ou sistêmica de um corante fotossensibilizador (FS) seguida da irradiação em baixas doses com luz visível de comprimento de onda adequado. A TFD tem dentre suas vantagens: repetição sem resistência ao fármaco; pode ser usada com outras terapias; tem dupla seletividade: não apenas o FS pode ser direcionado para as células ou tecido doente, mas também a luz é precisamente focalizada no local da lesão; o procedimento podendo ser repetido várias vezes, uma vez que não há efeitos tóxicos cumulativos. Os corantes são caracterizados pela sua habilidade de absorver luz visível. Alguns desses compostos são capazes de induzir ou participar de reações fotoquímicas, o que os fazem ser empregados como agentes terapêuticos. Este trabalho veio realizar uma revisão de literatura da aplicação da TFD na área da Odontologia, mostrando como essa terapia tem ampla indicação e já apresenta resultados satisfatórios, e que ainda tem sua aplicação muito restrita pela falta de conhecimento dos cirurgiõesdentistas seja no seu mecanismo de ação, seja na sua efetividade em destruição bacteriana.

Palavras-chave: FOTOQUIMIOTERAPIA; LASERS; PRODUTOS COM AÇÃO ANTIMICROBIANA.

\begin{abstract}
Photodynamic therapy (PDT) is based on systemic or topical administration of a photosensitizer dye followed by low dose irradiation of visible light with appropriate wavelength. The PDT has among its advantages: repetition without drug resistance, can be used with other therapies, has dual selectivity: not only the photosensitizer can be directed to the cells or diseased tissue, but also the light can be precisely targeted at the lesion site. The procedure can be repeated several times, since no toxic effects. The dyes are characterized by their ability to absorb visible light. Some of these compounds are able to induce or participate in photochemical reactions, which make them be employed as therapeutic agents. This work came to do a literature review of PDT in the field of dentistry, showing how this therapy has a broad statement and it produces satisfactory results, and which still has its application very constrained by lack of knowledge of dentists either in its mechanism action, whether in its effectiveness in bacterial destruction.
\end{abstract}

Key words: PHOTOCHEMOTHERAPY; LASERS; PRODUCTS WITH ANTIMICROBIAL ACTION. 


\section{INTRODUÇÃO}

Atualmente, pesquisas buscam por modalidades adjuvantes de tratamento antimicrobiano com menor possibilidade de efeitos colaterais para o indivíduo. Administrações sistêmicas e locais de antibióticos podem levar, entre outras consequências, à resistência bacteriana e desordens gastrointestinais. ${ }^{1}$

Em função do fato dos corantes absorverem luz com elevada eficiência em alguma região do espectro visível, alguns desses compostos são capazes de induzir ou participar de reações fotoquímicas, sendo alguns corantes empregados como agentes terapêuticos. Raab, em 1900, observou a morte de microrganismos quando expostos à luz solar e ao ar, na presença de certos corantes, o que seria o princípio de uma nova modalidade clínica conhecida como Terapia Fotodinâmica (TFD). Ela parte do princípio de que a interação de luz de comprimento de onda adequado com um composto não tóxico (fotossensibilizador) e oxigênio resulta em espécies reativas capazes de induzir à inviabilização de células. Isso é resultado da reação envolvida, decorrente da excitação eletrônica do corante pela luz, seguida de dois mecanismos principais de reação. ${ }^{2}$

Em 1907, von Tappeiner e Jodlbauer publicaram um livro-texto sobre essa terapia, definida como processo de fotossensibilização dependente de oxigênio, no tratamento de tumor cutâneo e destruição de partículas infecciosas. Nesse trabalho, descreveram suas experiências com eosina tópica a $5 \%$ e luz artificial para tratamento de câncer cutâneo não melanoma e de outras dermatoses, como lúpus vulgar e condiloma plano, postulando a ideia de que a eosina, assim como a acridina, depois de incorporada à célula, poderia produzir reação citotóxica quando exposta a fonte de luz adequada, na presença de oxigênio. ${ }^{3}$

\section{MeCANismo de AÇÃo}

A TFD baseia-se, então, na administração tópica ou sistêmica de um fotossensibilizador (FS) seguida da irradiação em baixas doses com luz visível de comprimento de onda adequado. $\mathrm{Na}$ presença de oxigênio encontrado nas células, o FS ativado pode reagir com moléculas na sua vizinhança por transferência de elétrons ou hidrogênio, levando à produção de radicais livres (reação do tipo I) ou por transferência de energia ao oxigênio (reação do tipo II), levando à produção de oxigênio "singlet".
As moléculas excitadas podem retornar ao estado fundamental emitindo energia na forma de fluorescência, por meio da liberação de fótons, ou progredir na cadeia de reações químicas, transformando-se na espécie reativa chamada triplete. As moléculas no estado triplete podem interagir diretamente com substratos biológicos e formar radicais livres, produzindo a denominada reação tipo I, ou podem transferir sua energia diretamente para o oxigênio celular e formar o oxigênio singlete altamente reativo e responsável pela morte celular, chamada de reação tipo II. ${ }^{5}$

Ambos os caminhos podem levar à morte celular e à destruição do tecido doente. O oxigênio "singlet" reage com os componentes celulares, pois os compostos orgânicos insaturados são suscetíveis à ação de $\mathrm{O} 2$. Como a primeira barreira para o O2 é a membrana celular, que contém lipídeos insaturados que podem ser danificados, ocorre a inviabilidade celular. Os hidroperóxidos resultantes formam espécies reativas de oxigênio (ROS) através de reações catalíticas e, uma vez que a reatividade das ROS não é específica, qualquer macromolécula da célula pode ser um alvo para TFD. Assim, a multiplicidade de alvos torna mais difícil desenvolver resistência celular. Inicialmente desenvolvida apenas com finalidade antineoplásica, a TFD passou também a ser utilizada como antimicrobiana, em especial frente à patógenos da cavidade oral. A relevância dessa descoberta está no fato de que estratégias alternativas de terapêutica antimicrobiana se tornam importantes na evolução dos métodos de controle de crescimento do biofilme na cavidade oral. ${ }^{4,6,7}$

O tratamento começa depois de um período de espera, após a administração ao paciente do FS. Quando a concentração do corante atinge o seu máximo no tecido lesado, procede-se à exposição do tumor ou do tecido infectado à radiação visível para a excitação do FS. A radiação, geralmente fornecida por um laser, é dirigida ao local do tratamento empregando-se um feixe de fibras ópticas. A fluência da radiação incidente deve se situar entre 100 e $200 \mathrm{~m} / \mathrm{Jcm}^{2}$ de modo a evitar o sobreaquecimento dos tecidos, o que reduziria a seletividade do processo. $O$ fotoprocesso inicial ocorre dentro de um espaço com diâmetro entre 10 e $50 \mathrm{~nm}$. Fatores químicos e biológicos tendem a propagar os efeitos a outros sítios, localizados a maiores distâncias da origem, o que faz necessário um estrito controle da biodistribuição do agente fototerapêutico a nível celular ou tissular. ${ }^{2}$

A terapia fotodinâmica tem vantagens como: repetição sem resistência ao fármaco; pode 
ser usada com outras terapias e promove uma destruição tecidual seletiva; há controle local agressivo do processo maligno ou infeccioso, sem dano extenso às estruturas normais circundantes. ${ }^{5}$ Tem a vantagem de dupla seletividade: não apenas o FS pode ser direcionado para as células ou tecido doente, mas também a luz pode ser precisamente focalizada no local da lesão. O procedimento pode ser repetido várias vezes, se necessário, uma vez que não há efeitos tóxicos cumulativos e é usualmente não invasivo. ${ }^{4}$

\section{Agente fotossensibilizador}

Entre as características ideais de um fotossensibilizador (FS) estão a pureza química, a capacidade de localização específica em tecido neoplásico, o intervalo pequeno entre a administração da droga e o acúmulo máximo no tumor, a meia-vida curta, a eliminação rápida do tecido normal, a ativação por comprimentos de onda com ótima penetração no tecido alvo e a capacidade de produzir grande quantidade de produtos citotóxicos. ${ }^{3}$ É necessário ainda que tenha baixa toxicidade no escuro, fazendo assim que essa terapia seja seletiva da área a ser tratada por meio da aplicação da luz em lugares estritos, e mesmo quando o fotossensibilizador atinja áreas indesejadas, não tenha ação tóxica; a fotossensibilidade não seja prolongada no organismo do paciente; formulação simples, reprodutível e estável (tempo mínimo de dois anos); facilidade de manuseio sintético que permita modificações para otimizar as propriedades desejáveis; facilidade de obtenção em escala industrial a custos reduzidos e com boa reprodutibilidade; facilidade de análise total dos componentes da fórmula. ${ }^{8}$

Um FS clinicamente adequado deve possuir no seu estado triplete excitado um tempo de vida de longa duração, de forma que o produto possa reagir eficientemente tanto com moléculas vizinhas como com o oxigênio o tempo suficiente para inativar células cancerígenas ou bacterianas. Deve também apresentar elevada absortividade molar na região espectral compreendida entre 600 e $1000 \mathrm{~nm}$, conhecida como "janela fototerapêutica”, onde a membrana celular apresenta considerável transparência à radiação eletromagnética. Possibilita-se assim uma boa penetração da luz $(2 \mathrm{a} 3 \mathrm{~cm})$ em tecidos levemente pigmentados, com risco mínimo de destruição generalizada dos componentes sadios que não contêm o FS. ${ }^{2}$
A maioria dos fotossensibilizadores é retida tanto nos tecidos normais como nos neoplásicos. O FS tende a se concentrar no tecido lesado ou nas células bacterianas, mas o mecanismo não está totalmente esclarecido, sendo que alguns fatores são descritos como responsáveis. A permeabilidade alterada da membrana das células tumorais e bacterianas, as fibras colágenas que interagem no tumor são imaturas e semelhantes às observadas em tecidos embrionários e em processo de cicatrização recente. Essas fibras imaturas apresentam grande capacidade de ligação às porfirinas, constituindo um local para retenção e acúmulo do FS. Outros fatores como rede linfática pouco desenvolvida, a presença de macrófagos e menor $\mathrm{pH}$ intracelular também levam à maior concentração do fármaco nas células tumorais. Sabe-se que a necrose e a apoptose são dependentes do FS e das condições do tratamento, não dependendo do ciclo celular ou de fatores genéticos. ${ }^{5}$

Inúmeros agentes fotossensibilizadores têm sido utilizados, destacando-se o azul de toluidina $\mathrm{O}$, cristal violeta, ftalocianina dissulfonada de alumínio, hematoporfirinas, tionina, protoporfirina e azul de metileno. A fotossensibilização depende do corante empregado, da sua concentração, fluência e intensidade de potência do laser, e da espécie bacteriana envolvida; a efetividade do corante está relacionada ao tempo de contato e sua concentração. ${ }^{9}$

A opção de corantes como agentes fotodinâmicos é interessante devido ao custo reduzido e aplicabilidade, sendo um exemplo o azul de metileno (AM). Este corante absorve na região de luz vermelha e produz oxigênio "singlet". Além disso, é bastante utilizado na área médica, por exemplo, para o tratamento de metahemoglobinemia, e tem sido considerado um fármaco para TFD. $\mathrm{O}$ azul de metileno tem um máximo de absorção na região de 660 nm (na janela fototerapêutica para TFD); sofre pouca reação de fotobranqueamento e exibiu um bom valor de atividade fotodinâmica, sendo compatível com o uso de LED. ${ }^{10}$

A aplicação de anestésicos tópicos, antes da irradiação, não deve ser feita, uma vez que o pH ácido dos anestésicos pode inativar quimicamente o fotossensibilizador. Em geral, a TFD é bem tolerada e, em alguns casos, a dor pode ser aliviada pelo uso de analgésicos orais, administrados uma hora antes do procedimento. ${ }^{11}$ 


\section{FONTE DE LUZ}

A melhor fonte de radiação tem sido descrita como sendo a que por um baixo custo forneça a maior quantidade de luz possível no máximo de absorção do fotossensibilizador, sem efeitos térmicos significativos. ${ }^{2}$

O laser é uma forma de radiação não ionizante, altamente concentrada, que em contato com os diferentes tecidos resulta em efeitos térmicos, fotoquímicos e não lineares de acordo com o tecido irradiado. Ao contrário de outras formas de radiação usadas terapeuticamente, como os raios $\mathrm{X}$, gama e nêutrons, a irradiação laser não é invasiva e é bem tolerada pelos tecidos. ${ }^{12}$

Para ativar as substâncias fotossensibilizadoras responsáveis pelo processo fotodinâmico, é necessário o uso de luz com frequência ressonante com o nível de absorção óptica da referida substância. Para o processo fotodinâmico, a luz ideal deve ter densidade de potência adequada e ser colimada; a alta colimação dos feixes laser somados às altas densidades de potência fazem desse o equipamento ideal para a ativação. Nesse caso, os lasers de vapor metálico, dye-lasers, lasers de semicondutores ou mesmo lasers de He-Ne são os mais utilizados. Entretanto, a monocromaticidade, que é uma das propriedades dos lasers, nem sempre é útil na TFD. Se o espectro de emissão do equipamento tem uma largura muito pequena, poucos serão os comprimentos de onda disponíveis para encontrar o melhor comprimento capaz de otimizar o processo de transferência de energia e, consequentemente, o processo fotodinâmico. ${ }^{13}$

O laser apresenta um comprimento de onda específico, correspondente ao pico de absorção do fotossensibilizante. Sua capacidade de emissão de luz monocromática de alta fluência, associada à precisão do foco, permite tratar pequenas lesões com mínimo dano ao tecido ao redor e em curto intervalo de tempo. Entretanto, para o tratamento de condições dermatológicas com TFD e sensibilizantes a base de protoporfirinas, os lasers não apresentam vantagens sobre as fontes de luz não coerentes, que são equipamentos mais baratos, práticos, e conseguem emitir grande campo de irradiação, possibilitando tratar maior área da superfície cutânea. ${ }^{3}$

As fontes de radiação empregadas são, em geral, lasers. Lasers sólidos tipo Nd:YAG têm sido empregados mais recentemente, mas ainda apresentam elevado custo. No entanto, empregando-se lasers Nd:YAG associados a alguns dispositivos ópticos, obtêm-se feixes de laser na faixa de 200 a $2000 \mathrm{~nm}$. Um exemplo desse sistema é o desenvolvido pela Opotek, Inc.(http://www.opotek.com/Selection.htm). Uma alternativa de custo intermediário são os lasers de diodo, dos quais se encontra modelos cobrindo praticamente todo o espectro visível e infravermelho próximo, o que atende a boa parte dos agentes fotossensibilizadores do mercado. Tais lasers fornecem luz pulsada de considerável potência com precisão sobre o tecido a ser irradiado, graças a sistemas de distribuição de fibras ópticas. Exemplos desses sistemas são os lasers cirúrgicos desenvolvidos para Terapia Fotodinâmica. Com o emprego de fotossensibilizadores de segunda geração, que apresentam elevada absortividade molar, o uso de diodos emissores de luz (LEDs) tem se tornado viável, possibilitando uma maior redução no custo dos procedimentos. ${ }^{2}$

\section{Principais INdicAÇões Na Odontologia}

A eliminação de microrganismos da cavidade bucal é fundamental para prevenir o risco de infecções locais e sistêmicas, e muitas substâncias antimicrobianas têm mostrado certa eficácia, porém a resistência de algumas bactérias gram-negativas a determinados medicamentos mostra a necessidade de métodos alternativos. ${ }^{14}$ Microrganismos como bactérias, fungos, leveduras e vírus também podem ser mortos por luz visível depois de tratamento com um fotossensibilizador apropriado e luz, em um processo denominado Inativação Fotodinâmica ("PDI, Photodynamic Inactivation"). ${ }^{4}$

A utilização de lasers capazes de matar microrganismos patogênicos surge como uma terapia auxiliar no tratamento odontológico preventivo e restaurador. A ação antimicrobiana do laser de baixa potência só começou a ser efetivamente estudada na última década, quando a terapia fotodinâmica inicialmente idealizada para o tratamento do câncer foi trazida para a odontologia. Enquanto no tratamento do câncer o alvo da TFD é promover a morte seletiva das células tumorais, no caso da odontologia surge uma nova perspectiva para o uso dessa terapia, tendo como alvo as células bacterianas envolvidas no desenvolvimento das lesões de cárie e da doença periodontal. ${ }^{15}$

Otratamento convencional para lesões de cáries é a remoção mecânica da dentina desmineralizada utilizando instrumentos cortantes. A TFD surge como alternativa à remoção dos microrganismos, pois nesta situação as bactérias da lesão cariosa 
podem ser eliminadas e o tecido desmineralizado pode ser preservado, evitando-se a exposição pulpar em lesões profundas. ${ }^{16}$

A redução de microrganismos patogênicos da superfície dental é um dos principais fatores envolvidos na preservação e no controle da doença cárie. Avaliando in vitro o efeito antimicrobiano da terapia fotodinâmica sobre os microrganismos mais diretamente relacionados ao surgimento de cárie em humanos, onde se utilizou laser diodo de $660 \mathrm{~nm}$, com densidade de energia de 28,8 $\mathrm{J} / \mathrm{cm}^{2}$, associado ao corante azul de toluidina O na concentração de $100 \mu \mathrm{g} / \mathrm{ml}$, observou-se total inibição de crescimento das suspensões bacterianas de Streptococcus mutans, Streptococcus sobrinus, Lactobacillus acidophilus e Lactobacillus casei, sugerindo que a terapia fotodinâmica é efetiva para a redução de bactérias cariogênicas. ${ }^{17}$

Avaliando a efetividade da TFD in vivo em cáries profundas de molares permanentes tratadas com azul de metileno $0,01 \%$ e irradiadas com laser diodo em baixa intensidade $(\lambda=660 \mathrm{~nm})$ por 90 segundos, houve redução estatisticamente significante tanto para $S$. mutans $(78.07 \%)$, como para Lactobacillus spp. (78.0\%) e para o total de bactérias viáveis $(76.03 \%)$. A terapia fotodinâmica é então efetiva para a eliminação das bactérias presentes na dentina de lesões de cárie profundas, assegurando a preservação de estrutura dental durante o tratamento. ${ }^{16}$

A doença periodontal é causada por uma série de espécies de bactérias patogênicas que, com uma vasta gama de espécies compatíveis com o hospedeiro, formam complexos nos biofilmes subgengivais e são responsáveis pela inflamação clínica e destruição periodontal. Um fotossensibilizador pode ser injetado dentro da cavidade periodontal, seguido de iluminação com fibra ótica inserida dentro da área afetada. Essa técnica mantém o efeito bactericida confinado na lesão, de forma que a microflora benéfica em outros locais da boca pode permanecer intacta. De forma similar, o mesmo procedimento clínico poderia ser aplicado nas desinfecções de cáries na superfície dos dentes. ${ }^{4}$

A doença periodontal tem como fator etiológico os microrganismos do biofilme subgengival na superfície dos dentes, e o Actinobacillus actinomycetemcomitans ocupa um papel importante na ecologia das periodontites localizadas e generalizadas. A TFD vem se consolidando como alternativa para o uso de antibióticos, e se apresenta como um método para auxílio dos pacientes portadores da doença.
Investigando a ação do verde malaquita (VM) associado à irradiação laser em baixa intensidade contra o $A$. actinomycetemcomitans em suspensão, observou-se que o $A$. actinomycetemcomitans pode ser morto pela irradiação laser vermelho em baixa intensidade na presença do VM, sendo ainda verificado que somente a irradiação laser não foi capaz de danificar as células bacterianas. ${ }^{18}$

O principal objetivo do tratamento periodontal é o restabelecimento da saúde pela remoção dos depósitos bacterianos e calcificados presentes na superfície radicular, e seu sucesso depende da eliminação dos agentes que promovem a destruição dos tecidos. No entanto, a terapia mecânica não é capaz de eliminar os patógenos periodontais devido à capacidade que alguns microrganismos apresentam de invadir o interior dos tecidos, muitas vezes inacessíveis aos instrumentos. ${ }^{9}$

Existe atualmente um grande interesse no efeito antimicrobiano pelo uso dessa terapia, o que pode ser bastante útil na periodontia, já que um grande número de microrganismos, incluindo bactérias, pode ser eliminado por ela. Todavia, ainda existe a necessidade de pesquisas in vivo a fim de determinar as doses específicas para cada população de bactéria, para assim obter o efeito bactericida ideal. ${ }^{11}$ Os resultados de estudos encontrados ainda são controversos. A TFD antimicrobiana frente a bactérias periodontais in vitro foi capaz de inativar $63 \%$ das bactérias, enquanto in vivo seu máximo de inativação chega a $32 \%$, o que mostra a interferência do meio no processo fotodinâmico. ${ }^{19}$

O biofilme formado por C. albicans é a causa mais frequente de infecções fúngicas da mucosa oral, possuindo uma comprovada resistência a antifúngicos. No entanto, poucos trabalhos na literatura relatam o comportamento e a resposta de C. albicans organizado em biofilme frente à terapia fotodinâmica. ${ }^{20}$

Empregando o laser diodo InGaAlP em distintas dosimetrias associado ao azul de metileno na concentração de $100 \mathrm{Rg} / \mathrm{mL}$ para avaliar in vitro a ação da TFD sobre a viabilidade da Candida sp. e de células epiteliais sobre amostras de 38 pacientes portadores de candidose oral e em culturas de células HEp-2, observou-se que houve inativação significativa da Candida sp. A dosimetria de 450 $\mathrm{J} / \mathrm{cm}^{2}$ foi a mais eficaz, e a Candida albicans foi significativamente mais sensível ao tratamento, com inativação média de $50,44 \%$ das UFCs, enquanto as outras espécies apresentaram inativação média de $41,18 \%$. Depois de submetidas à TFD, as células HEp-2 exibiram viabilidade 
média, independentemente da dosimetria aplicada, de $70,81 \%$, mostrando que as células epiteliais HEp-2 foram menos sensíveis à TFD do que a Candida $s p$., fato que indica a existência de uma margem de segurança para aplicação in vivo. ${ }^{21}$

A utilização do laser de baixa potência é proposta como um coadjuvante no tratamento do herpes labial, com a vantagem de diminuir a frequência de aparecimento das lesões, proporcionando satisfação e conforto aos pacientes. Utilizando a terapia fotodinâmica para o tratamento do herpes labial na fase de vesícula associada à terapia com laser de baixa potência para reparação da lesão, observou-se completa resolução do caso em uma semana, sendo que uma considerável melhora dos sinais e sintomas do herpes labial foi obtida seis horas após a terapia fotodinâmica. Houve rápida reparação da ferida, o tratamento foi indolor e bem aceito pela paciente. Uma das opções de tratamento do herpes labial na fase de vesícula é o emprego do laser de alta potência, porém, os pacientes relatam muita dor, sendo geralmente descrita como uma sensação de agulhadas ou queimadura, provocada pelo aumento de temperatura do laser. ${ }^{22}$

A TFD na Odontologia também pode ser indicada para aquela que foi sua primeira finalidade: a destruição de células de possível caráter maligno. Seguindo essa premissa, Silva et al. $(2006)^{23}$ incluem entre as modalidades de tratamento para a remoção do epitélio alterado de lesões labiais de queilite actínica a terapia fotodinâmica associada com a aplicação de ácido 5-aminolevulínico (5-ALA), além da curetagem e vermelhectomia.

\section{Discussão}

A terapia envolvendo o uso do Laser de baixa intensidade tem despertado atenção de muitos pesquisadores principalmente o seu uso na terapia fotodinâmica. Esta, definida como a irradiação de células/bactérias marcadas por uma espécie de oxigênio reativo produzido por meio de uma droga fotossensibilizadora e luz com comprimento de onda apropriado, tem apresentado resultados animadores e efetivos em promover a morte bacteriana. ${ }^{9}$

Estudos já evidenciaram que a associação de um corante (em concentração ideal) a um laser de baixa potência é capaz de reduzir e/ ou inibir o crescimento de bactérias em placa bacteriana, contribuindo de forma expressiva as evidências que conduzem ao desenvolvimento da
TFD no tratamento de lesões de cárie. Além da seletividade, esta modalidade terapêutica permite menor invasividade, causando em consequência menores riscos de comprometimento pulpar de curto em longo prazo. Os estudos apresentados corroboram no sentido que a terapia fotodinâmica é então efetiva para a eliminação das bactérias cariogênicas presentes na dentina de lesões profundas, tendo ainda como grande vantagem assegurar maior preservação de estrutura dental quando da aplicação deste tratamento. ${ }^{14,16,17}$

O caráter atraumático da terapia tem implicações, principalmente no que diz respeito ao tratamento de pacientes pediátricos e especiais. ${ }^{15}$ Entretanto, seu uso é indicado ainda como terapia adjuvante na maioria dos casos, sendo inicialmente empregados instrumentos rotatórios e em seguida feita a aplicação da terapia fotodinâmica, reduzindo então o número de microrganismos no tecido remanescente, e por consequência a possibilidade de reincidência.

A terapia mecânica aplicada isoladamente no tratamento periodontal não é capaz de eliminar os patógenos devido à capacidade que alguns microrganismos apresentam de invadir o interior dos tecidos, muitas vezes inacessíveis aos instrumentos. Por isso, a busca por métodos coadjuvantes ao tratamento periodontal tem aumentado, e o efeito da terapia fotodinâmica nos patógenos periodontais mostrou-se eficaz na redução de bactérias periodontopatogênicas, apresentando-se como um coadjuvante promissor à terapia periodontal básica, sendo necessários novos estudos para se determinar parâmetros específicos do laser e do agente fotossensibilizador, para tornar a terapia fotodinâmica mais efetiva e previsível. Não existe na terapêutica da doença periodontal dados clínicos e microbiológicos suficientes que suportem o uso da PDT como antimicrobiano adjunto à terapia mecânica. Mais estudos clínicos são necessários para demonstrar os benefícios adicionais da PDT em relação ao tratamento convencional, e para determinar suas melhores condições de aplicação. 9,19,24

A terapia fotodinâmica também tem se mostrado eficiente contra a Candidose, entretanto é consenso observar que é pouco o estudo voltado para o tratamento da C. albicans, sendo necessário um maior número de estudos para consolidar este tratamento. ${ }^{20,21}$

Apesar do vasto campo de aplicação da TFD e do grande apelo clínico e comercial da técnica, dois fatores dificultam a disseminação do tratamento: o custo dos medicamentos e equipamentos, além 
da falta de conhecimento da técnica pela classe médica e odontológica. Os fármacos utilizados para a TFD, cujos princípios ativos são sintéticos, são economicamente inacessíveis à maioria da população devido às dificuldades na produção e alto investimento no desenvolvimento destes. ${ }^{10}$ Diante da literatura apresentada, podemos observar que, de fato, a consagração do laser como terapia, exige um conhecimento da energia aplicada, uma investigação dos efeitos que produz no organismo e a aplicação de uma correta metodologia. ${ }^{12}$

\section{Conclusão}

Com a seguinte revisão da literatura, podemos concluir que a terapia fotodinâmica se mostra como uma relevante e ascendente proposta de alternativa terapêutica para o tratamento odontológico, em especial no que se refere a sua atividade antimicrobiana, devido ao seu baixo custo, fácil empregabilidade e boa efetividade.

\section{REFERÊNCIAS BIBLIOGRÁFICAS}

1. Sigusch B. W., Engelbrecht M., Volpel A., Holletschke A., Pfister W., Schutze J. Fullmouth antimicrobial photodynamic therapy in Fusobacterium nucleatum- infected periodontitis patients. J Periodontol. 2010. 81(7): 975-81.

2. Machado A. E. H. Terapia fotodinâmica: princípios, potencial de aplicação e perspectivas. Rev Quím Nova. 2000. 23(2): 237-43.

3. Issa M. C. A., Manela-Azulay M. Terapia fotodinâmica: revisão da literatura e documentação iconográfica. An Bras Dermatol. 2010. 85(4): 501-11.

4. Perussi J. R. Inativação fotodinâmica de microrganismos. Rev Quim Nova. 2007. 30(4): 988-94.

5. Ferreira I., Rahal S. C., Ferreira J., Corrêa T. P. Terapêutica no carcinoma de células escamosas cutâneo em gatos. Ciência Rural. 2006. 36(3): 1.027-1.033.

6. Takasaki A. A., Aoki A., Mizutani K., Schwarz F., Sculean A., Wang C. Y. et al. Aplication of antimicrobial photodynamic therapy in periodontal and peri-implant diseases. Periodontology. 2000, 2009. 51: 109-140.

7. Soukos N. S., Goodson J. M. Photodynamic therapy in the control of oral biofilms. Periodontology. 2000, 2011. 55: 143-166.

8. Simplício F. I., Maionchi F., Hioka N. Terapia fotodinâmica: aspectos farmacológicos, aplicações e avanços recentes no desenvolvimento de medicamentos. Rev Quim Nova. 2002. 25(5): 801-807.

9. Almeida J. M., Garcia V. G., Theodoro L. H., Bosco A. F., Nagata M. J. H., Macarini V. C. Terapia fotodinâmica: uma opção na terapia periodontal. Arq Odontol. 2006. 42(3): 161256.

10. Peloi L. S. Estudos da aplicação do corante azul de metileno em terapia fotodinâmica. Dissertação de mestrado da Universidade Estadual de Maringá. Maringá. 2007.

11. Neves D. R. Terapia fotodinâmica para tratamento de múltiplas lesões no couro cabeludo na síndrome do nevobasocelular Relato de caso. An Bras Dermatol. 2010. 85(4): 545-8.

12. Henriques A. C. G., Maia A. M. A., Cimões R., Castro J. F. L. A laserterapia na odontologia: propriedades, indicações e aspectos atuais. Odontol Clín-Cient. 2008. 7(3): 197-200.

13. Ribeiro J. N., Flores A. V. Terapia Fotodinâmica: uma luz na luta contra o câncer. Rev. Physicae. 2005. 5(5).

14. Bevilacqua IM, Pacheco MTT, Nicolau RA. Ação do laser de baixa potência associado à substâncias fotoativadoras na redução microbiana (revisão da literatura). Resumo de anais do IX Encontro Latino Americano de Iniciação Científica e $V$ Encontro Latino Americano de Pós-Graduação Universidade do Vale do Paraíba. 2006.

15. Zanin ICJ, Brugnera Jr. A., Zanin F., Gonçalves R. B. Terapia Fotodinâmica na Odontologia (TFD). Rev Gauc Odontol. 2003. 51(3): 179-182.

16. Guglielmi CAB. Avaliação microbiológica in vivo de lesões de cárie profundas tratadas pela terapia fotodinâmica. São Paulo; s.n. 2009. 112 p. ilus., tab., graf. (BR).

17. Zanin ICJ. Steiner-Oliveira C., Brugnera Jr. A., Gonçalves R. Aplicação da terapia fotodinâmica na descontaminação bacteriana. Rev Assoc Paul Cir Dent. 2002: 56 (Supl.): 7-11.

18. Prates RA, Yamada Jr. AM, Suzuki L. C., Hashimoto MCE, Cai S., Soares S. G., et al. Bactericidal effect of malachite Green and red laser on Actinobacillus actinomycetemcomitans. J. Photochem Photobiol. 2007. 86:70-76.

19. Fontana C. R., Abernethy A. D., Som S., 
Ruggiero K., Doucette S., Marcantonio R. C. et al. The antibacterial effect of photodynamic therapy in dental plaque-derived biofilms. J. Periodont Res. 2009. 44: 751-759.

20. Suzuki L. C. Desenvolvimento de biofilme formado por Candida albicans in vitro para estudo da terapia fotodinâmica. São Paulo; s.n. 2009. 49 p. ilus., tab., graf. (BR).

21. Marinho S. A. Efeito da terapia fotodinâmica (PDT) sobre culturas de Candida sp. e de células epiteliais: estudo in vitro. Porto Alegre; s.n. 2006. 163 p. ilus., tab., graf. (BR).

22. Marotti J. Tratamento do herpes labial pela terapia fotodinâmica. Rev Assoc Paul Cir Dent. 2008. 62(5): 370-3.
23. Silva F. D., Daniel F. I., Grando L. J., Calvo M. C., Rath I. B. S., Fabro S. M. L. Estudo da prevalência de alterações labiais em pescadores da ilha de Santa Catarina. Rev Odonto Ciênc. 2006. 21(51): 37-42.

24. Carvalho V. F., Lubisco M. A., Alves V. T., Gonçalves C. C. J. S., Conde M. C., Pannuti C. M. et al. Terapia fotodinâmica em periodontia clínica. Rev Periodont. 2010. 20 (3): 7-12.

Submetido em: 28-8-2011

Aceito em: 2-5-2012 